admission and compulsory detention to a psychiatric hospital.

CArstairs, V. \& Morris, R. (1989) Deprivation: explaining differences in mortality between Scotland and England and Wales. British Medical Journal, 299, 886-889.

_ \& (1990) Deprivation and health in Scotland. Health Bulletin, 48, 162-175.

HIRSCH, S. R. (1988) Psychiatric Beds and Resources: Factors Influencing Bed Use and Service Planning. Report of a Working Party of the Section for Social and Community Psychiatry of the Royal College of Psychiatrists, pp. 4-13. London: Gaskell.

JARMAN, B. (1984) Underprivileged areas: validation and distribution of Scores. British Medical Journal, 289, 1587-1592.

ThORNICROFT, G. (1991) Social deprivation and rates of treated mental disorder. British Journal of Psychiatry, 158, 475-484.

LESLEY J. ROBERTSON
ROBIN G. MCCREADIE
$\begin{aligned} & \text { Department of Clinical Research } \\ & \text { Crichton Royal Hospital } \\ & \text { Dumfries } \\ & \text { Scotland }\end{aligned}$

\section{Depression and polycythaemia}

SIR: The article by Murray \& Hodgson (Journal, June 1991, 158, 842-844), regarding a patient with depression and polycythaemia, emphasises the potential for cerebral ischaemia in this disease which we have noted can cause psychiatric symptoms (Aker et al, 1990). This is brought about by the mechanism of blood sludging which can be reversed or prevented by anticoagulant therapy (Knisely, 1968).

We have found the use of anticoagulant therapy very useful for dementia due to arteriosclerosis (Walsh et al, 1972), and see no reason why it would not work well in polycythaemia patients who do not respond to venesection. It would be well worth a trial before resorting to electroconvulsive therapy. Since this approach focuses on relieving the primary cause of the mental upset, cerebral ischaemia, the results could be far superior to ECT.

Aker, J. B., Walsh, A. \& Beam, J. (1977) Mental Capacity: Medical and Legal Aspects of Aging (1990 annual supplement). Colorado Springs, CO: Shepard's/McGraw-Hill.

KNISELY, M. H. (1968) Intravascular agglutination (blood sludging). In Handbook of Physiology. Baltimore, Md: Williams and Wilkins.

Walsh, A. C., Walsh, B. \& Melaney, C. (1972) Senile-presenile dementia: follow-up data on an effective psychotherapyanticoagulant regimen. Journal of the American Geriatric Society, 26, 467-470.

\section{N. Dithridge Street}

Arthur C. Walsh

Pittsburgh

Pennsylvania 15213

$U S A$

\section{What's in a name?}

SIR: Power-Smith (Journal, August 1991, 159, 296) was bemused with the term 'Consultant Physician (Mental Health)' and canvassed for other appellations. The following are lists (Walter, 1991) of formal and slang terms which have, at various times, been used to designate members of our profession:

(a) Formal appellations: clerical mad doctor, psychopathic practitioner, alienist, mental hygienist, psychiatrist, psychotherapist, therapist, psychoanalyst, analyst, nerve specialist, mental specialist.

(b) Slang appellations: mad-doctor, nut-doctor, looney-doctor, crazy-doctor, bug-doctor, squirrel-doctor, psycho, psyche, psych, sickey-ackey, sky-high-atrist, headpeeper, couch-doctor, trick-cyclist, headshrinker, shrinker, shrink, straightener.

The number, range and nature of such designations attest historical changes in the treatment of mental illness, euphemistic influences and the ambivalent attitude displayed towards those who manage mental illness. Other factors may also play a part. It may not be coincidental that the word 'psychotherapist' became fragmented into 'psycho, the rapist'(Mackay, 1990) in Australia at a time when there was a much publicised case of therapist-patient sexual contact. The relevance to our profession is that the maintenance of moral and ethical standards of care may not prevent the introduction of unsavoury appellations but will also not actively encourage them.

Mackay, C. (1990) Between the lines. The Sydney Daily Telegraph. May 11.

WALTER, G. (1991) The naming of our species: appellations for the psychiatrist. Australian and New Zealand Journal of Psychiatry. 25, $123-128$.

\section{The Northside Clinic}

Sydney, NSW

Australia

\section{Monozygotic male triplets discordant for psychosis}

SIR: Differences in brain morphology between monozygotic twins discordant for schizophrenia suggest brain damage as a cause of the psychosis. I report a rare occurrence, a persisting schizoaffective psychosis in one of monozygotic male triplets with MRI findings suggesting abnormality in the unaffected siblings. The diagnoses were made with the Schedule for Affective Disorders and Schizophrenia (SADS).

The triplets were born of a healthy 19-year-old married woman. The normal pregnancy ended at 36 
weeks in an uncomplicated six-hour labour and the delivery of three healthy boys. Their birthweights, in birth order, were $1.91 \mathrm{~kg}(4 \mathrm{lb} 4 \mathrm{oz}), 1.77 \mathrm{~kg}$ ( $3 \mathrm{lb}$ $15 \mathrm{oz})$ and $1.77 \mathrm{~kg}$ ( $3 \mathrm{lb} 15 \mathrm{oz})$. No neonatal disorders of consequence were recorded in the maternity book or recollected by the mother.

They have been proven monozygotic by DNA fingerprinting: zygosity, determined by CELLMARK Diagnostics, used the multilocus probes 33.15 and 33.6 on a sample of venous blood from each triplet, and the three sets of $\mathbf{4 8}$ bands identified were identical.

The second-born developed a major depression at 32 years of age, which failed to respond to drugs and psychotherapy. Six months after onset, delusions, hallucinations and passivity experiences occurred which required in-patient care, neuroleptics and ECT. Three years on, medication with neuroleptics and lithium continues to be required to control delusions and depressed mood. Employment has failed. Both siblings remain well apart from intermittent episodes of depression not severe enough to interfere with work.

The mother has a history of intermittent depressive disorder and two episodes of major depression. The father has no psychiatric history; his two siblings are said to have primary cerebellar ataxia.

Magnetic resonance imaging of all three triplets, read blind to the clinical facts, showed the right temporal horn to be larger than the left in the first born sibling, possibly also in the last born and within normal limits in the affected second-born sibling. (MRI sequences: saggital $T_{1} \mathrm{~W}$ and axial $T_{2} \mathrm{~W}$ (proton density and TE 90) spin-echo sequences of the entire brain, amplified by coronal $T_{1} \mathrm{~W}$ inversionrecovery sequences of $5 \mathrm{~mm}$ thickness of the temporal lobes).

These findings are against brain structural differences causing the discordancy for psychosis, unless the abnormalities are protective. The most informative possible explanation is a post-zygotic change in the genome of the affected sibling which may ultimately be identifiable; the most likely is an unknown environmental influence on the developing brain.

This letter is published anonymously to prevent identification of the triplets.

\section{Chloroquine-induced psychiatric complications}

SIR: I would like to draw to the attention of Dr Lovestone that the case reported by him was not the first patient with a true manic episode without confusion in response to chloroquine (Journal, July $1991,159,164-165)$. We have previously reported 30 cases (Bhatia et al, 1988a) (age range 4-36 years; 21 females and 9 males). Organic psychosis was the most common diagnosis (16 cases) followed by paranoid schizophrenia in six, manic-depressive psychosis (MDP) (mania) in two, MDP (depression) in two, anxiety neurosis in two and grand mal seizures in two. When the mode of intake of chloroquine was compared with a control group (the cases who were prescribed chloroquine for malaria but did not develop any psychiatric complication), the patients who took chloroquine with milk were significantly over represented in the study group $(P<0.001)$. The dose, salt of the drug (phosphate or sulphate) and whether the intake of drug was on an empty stomach or after meals, were however, not found to be statistically significant. Headache and sleeplessness were reported significantly more by the patients who developed psychiatric complications. The duration of onset of these complications was two to seven days. Out of 30 cases, 26 recovered within three weeks of discontinuation of chloroquine, whereas the remaining four cases took about 12 weeks to recover. Although six cases were below 12 years of age (Bhatia et al, 1988b), there was no statistically significant difference between the age and sex of cases in study and control groups.

The mechanism by which chloroquine can induce psychosis is still not fully understood. One can draw an analogy with various theories put forward to explain quinacrine psychosis. Engel et al (1947) reported that quinacrine acts as a central stimulant through an unknown mechanism. The hypotheses put forward to explain these psychiatric complications include a drug-induced cholinergic imbalance, prostaglandin-E-antagonism (Malek-Ahmadi, 1981) dopaminergic overactivity and a predisposing factor of glucose-6-phosphate dehydrogenase deficiency (Nasr, 1981). To date, none of these hypotheses have been experimentally evaluated.

Bhatia, M. S., Singhal, P. K. \& Dhar, N. K. (1988a) Psychiatric complications of chloroquine. Annals of National Academy of Medical Sciences (India), 24, 223-228.

$-\frac{1}{2}-(1988 b)$ Chloroquine-induced psychosis. Indian Pediatrics, 25, 258-262.

Engel, G. L., Romano, J. \& Ferris, F. B. (1947) Effect of quinacrine (atabrine) on the central nervous system. Archives of Neurology. 58, 337-339.

Malek-Ahmad, P. (1981) Toxic psychosis following use of quinacrine. Journal of Clinical Psychiatry, 42, 481.

NASR, S. (1981) Toxic psychosis following use of quinacrine. Journal of Clinical Psychiatry, 42, 481.

M. S. ВнатіА

Department of Psychiatry

University College of Medical Sciences

Delhi-110095

India 